\title{
Carbon Felt-Based Reagentless Amperometric Hydrogen Peroxide Biosensor Using Co-Immobilized Toluidine Blue $O$ and Horseradish Peroxidase
}

\author{
Yasushi HASEBE, * Ryouichi MURAO, and Shunichi UCHIYAMA
}

Department of Applied Chemistry, Faculty of Engineering, Saitama Institute of Technology (1690 Fusaiji, Okabe, Saitama 369-0293, Japan)

Received May 18, 2000 ; Accepted July 11, 2000

\begin{abstract}
The electron-transfer mediator, toluidine blue $O$ (TBO), was covalently immobilized together with horseradish peroxidase (HRP) onto cyanuric chloride-activated porous carbon felt (CF) in order to fabricate a second generation reagentless $\mathrm{H}_{2} \mathrm{O}_{2}$ biosensor. Cyclic voltammetry $(\mathrm{CV})$ indicated that the immobilized TBO efficiently mediates electrons from the $\mathrm{CF}$ electrode to the redox active center of the HRP. The resulting CF electrode (TBO-HRP-CF) exhibited amperometric responses to $\mathrm{H}_{2} \mathrm{O}_{2}$ with the relatively fast response time of $\sim 15 \mathrm{~s}$ in the concentration range from $5 \times$ $10^{-5} \mathrm{M}$ to $5 \times 10^{-3} \mathrm{M}\left(\mathrm{M}=\mathrm{mol} \mathrm{dm}{ }^{-3}\right)$ with a detection limit of $5 \times 10^{-5} \mathrm{M} \mathrm{H}_{2} \mathrm{O}_{2}$ in $0.1 \mathrm{M}$ phosphate buffer (pH 7.0).
\end{abstract}

Key Words : Biosensor, Carbon Felt, Horseradish Peroxidase, Toluidine Blue O, Hydrogen Peroxide

\section{Introduction}

The determination of hydrogen peroxide is important in many fields such as chemical, pharmaceutical, environmental analysis and the food industry. Since biosensors are powerful tools with simplicity and high sensitivity, various types of peroxidase-modified electrodes have been proposed for the determination of $\mathrm{H}_{2} \mathrm{O}_{2}$. Among them, the mediator-coupling enzyme sensor (so called, second generation enzyme sensor) is attractive for enhancement of the selectivity and sensitivity. ${ }^{1-5)}$ As compared with a solution-phase mediator, the immobilization of mediators together with an enzyme onto an electrode surface is more preferable for practical and multiple use. In this case, the design of the interface of the mediator/ enzyme/electrode is very important for efficient electronic communications.

A porous carbon felt (CF) sheet, which is a microelectrode ensemble (ca. $7 \mu \mathrm{m}$ diameter carbon fiber) with a random three dimensional structure, has extremely high and effective surface area $\left(0.2 \sim 0.7 \mathrm{~m}^{2} \mathrm{~g}^{-1}\right)$ and allows large measurable current density. ${ }^{6}$ Based on these features, the $\mathrm{CF}$ has been utilized for macro-electrolysis, ${ }^{7}$ ) couloamperometry, ${ }^{8)}$ biosensor recognition elements, $9^{-11)}$ and flow-through reactors. ${ }^{12,13)}$ Additionally, the pyrolytic graphite edge plane of $\mathrm{CF}$ possesses reactive functional groups such as hydroxyl, carbonyl and carboxyl groups, which are attractive for chemical coupling and modification. ${ }^{7}$ ) Therefore, if the enzyme and electrochemical mediator can be easily immobilized at the CF surface and the immobilized mediator efficiently shuttles the electron from the CF electrode to the immobilized enzyme active center, this CF has potential utility not only as a recognition layer for second generation biosensors but also as a enzyme-couloamperometric cell in which the mediator-assisted bioelectrocatalytic reaction can be easily monitored at a lower applied potential.

In this study, as a first approach of constructing the CF-based reagentless second generation biosensor, a water soluble electron-transfer mediator, toluidine blue $\mathrm{O}$ (TBO), and horseradish peroxidase (HRP) were coimmobilized at the cyanuric chloride-activated surface of the porous $\mathrm{CF}$ through the amino group of TBO and HRP by a simple one-step procedure. A preliminary study by cyclic voltammetry (CV) and controlledpotential amperometry in order to evaluate the fundamental performance characteristics of the CF-based mediated $\mathrm{H}_{2} \mathrm{O}_{2}$ sensor has been completed.

\section{Experimental}

A porous carbon felt (CF) obtained from Nippon Carbon Ltd., (GF-20-3F, baked at $2000^{\circ} \mathrm{C}, 3 \mathrm{~mm}$ thickness) was cut into a round sheet $(10 \mathrm{~mm}$ diameter, $3 \mathrm{~mm}$ thickness), and was used as a matrix for immobilization of the enzyme and mediator. Horseradish peroxidase (HRP, EC 1.11.1.7., 100>units $\mathrm{mg}^{-1}$ ) was purchased from Wako Pure Chemicals and used as received. Toluidine blue O (TBO), cyanuric chloride, and 30\% hydrogen peroxide were also obtained from Wako Pure Chemicals. All of the other chemicals were of the highest grade available. All the solutions were prepared with doubly distilled water.

Prior to the modification experiment, a $\mathrm{CF}$ was thoroughly washed with distilled water and dried at $120^{\circ} \mathrm{C}$ for $14 \mathrm{~h}$. It was then immersed in toluene containing $5 \mathrm{mM}$ cyanuric chloride for $2 \mathrm{~h}$ at room temperature, and the remaining $\mathrm{OH}$ groups on the $\mathrm{CF}$ surface were activated. After washing with toluene to remove any adsorbed cyanuric chloride, the $\mathrm{CF}$ was dried in a vacuum desiccator. Next, this activated $\mathrm{CF}$ was immersed in a mixed solution of TBO $(1 \mathrm{mM})$ and HRP $\left(0.4 \mathrm{~g} \mathrm{dm}^{-3}\right)$ for 7 days at 
room temperature. The TBO/HRP co-immobilized $\mathrm{CF}$ is called TBO-HRP-CF hereafter.

The electrochemical measurements were carried out using a three-electrode system comprising the TBO-HRP$\mathrm{CF}$ with a platinum lead wire as the working electrode, $\mathrm{Ag} / \mathrm{AgCl}$ reference electrode (TOA HS-205C), and a platinum wire auxiliary electrode. The cyclic voltammetry (CV) measurements were carried out with an electrochemical analyzer (ALS-600A) interfaced to a DELL computer. A constant-potential mode operation was carried out with potentio/galvanostat (Hokuto Denko, HA-151) and X-t recorder (Pantos, unicorder U-228). All the electrochemical experiments were carried out in $50 \mathrm{~mL}$ of $0.1 \mathrm{M}$ phosphate buffer $(\mathrm{pH} 7.0)$ at laboratory ambient temperature $\left(22-24^{\circ} \mathrm{C}\right)$. All the electrolyte solutions were thoroughly deoxygenated by bubbling nitrogen through the solution for at least $10 \mathrm{~min}$ prior to the measurements.

\section{Results and Discussion}

Figure 1 shows typical cyclic voltammograms for the TBO-HRP-CF with and without $2 \mathrm{mM} \mathrm{H}_{2} \mathrm{O}_{2}$ in $0.1 \mathrm{M}$

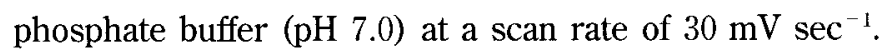
In the absence of $\mathrm{H}_{2} \mathrm{O}_{2}$, the linked TBO exhibits an electrochemically quasi-reversible redox process. (Fig. 1a). Table 1 summarizes the electrochemical parameters obtained for the bare and TBO/HRP modified $\mathrm{CF}$ electrodes. The midpoint potential, $E_{1 / 2}$, of the TBO-HRP-CF is more positive compared with that of the bare $\mathrm{CF}$ with dissolved TBO. It has been reported that the derivatization of the aromatic amino group of the phenothiazine derivatives induces a positive shift in the redox potential because of a decrease in the electron-donating properties of the nitrogen atom after derivatization. ${ }^{14}{ }^{15}$ ) Additionally, the anodic and cathodic peak separation, $\Delta E$, expanded after immobilization. These tendencies are quite similar to the previous reports in which TBO was covalently in-

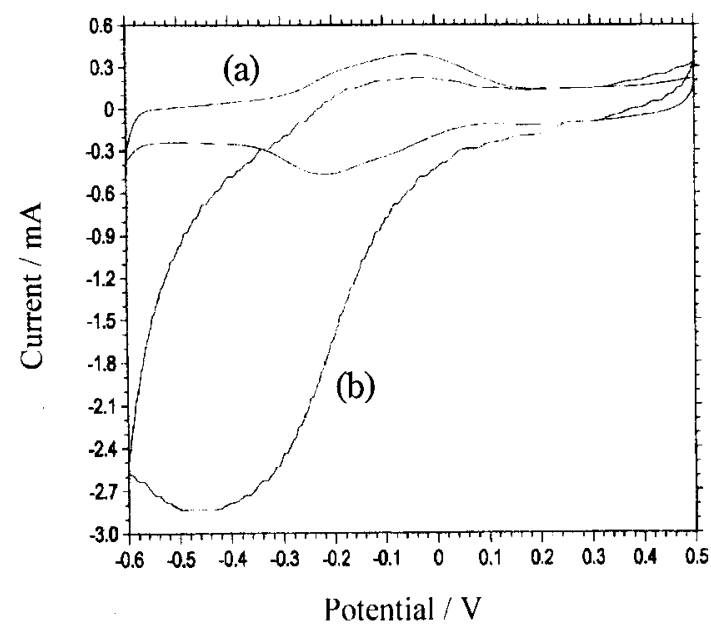

Fig. 1 Cyclic voltammograms of TBO-HRP-CF electrode in the absence (a) and presence (b) of $2 \mathrm{mM}$ of $\mathrm{H}_{2} \mathrm{O}_{2}$ in $0.1 \mathrm{M}$ phosphate buffer ( $\mathrm{pH} \mathrm{7.0)}$ at scan rate of $30 \mathrm{mV} \mathrm{s}^{-1}$. The $\mathrm{CV}$ measurements in the presence of $\mathrm{H}_{2} \mathrm{O}_{2}$ were started after an initial stirring of $10 \mathrm{~s}$ after the addition of $\mathrm{H}_{2} \mathrm{O}_{2}$ into the electrolyte solution. troduced at the self-assembled monolayer adsorbed on the Au electrode. ${ }^{15)}$ The anodic and cathodic peak currents were proportional to the scan rate $(v)$ up to 500 $\mathrm{mV} \mathrm{s}^{-1}$, indicating that the observed $\mathrm{CV}$ peaks are due to the electron transfer process of the TBO covalently bound on the $\mathrm{CF}$ surface through its amino group.

Upon the addition of $2 \mathrm{mM} \mathrm{H}_{2} \mathrm{O}_{2}$, the voltammetry was changed; an increase in the reduction current and disappearance of the oxidation current (shown in Fig. 1b). These electrocatalytic responses depended on the $\mathrm{H}_{2} \mathrm{O}_{2}$ concentration and temporary stirring time. From the control experiments with the bare and the TBO-modified CFs (similarly prepared without HRP), the direct and TBO-mediated electroreductions of $\mathrm{H}_{2} \mathrm{O}_{2}$ were negligible under the present experimental conditions. These results strongly indicate that the immobilized HRP retained its catalytic activity, and the attached TBO efficiently shuttled the electrons between the HRP active center and the $\mathrm{CF}$ electrode. It can be considered that a random threedimensional structure of the $\mathrm{CF}$, where individual carbon fibers exist within very small dimensions, would contribute to enhancing the electrical communication between the TBO and HRP attached independently at the carbon fiber electrode surface.

The effect of the applied potential upon the steady-

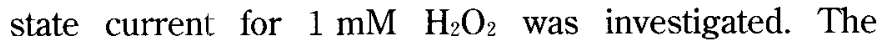
steady-state current increased by a negative shift in the applied potential, and the saturation tendency was observed at a potential more negative than about $-0.4 \mathrm{~V}$ (vs. $\mathrm{Ag} / \mathrm{AgCl}$ ). Figure 2 shows the time responses of the

Table 1 Electrochemical properties of bare and TBO/HRP modified CFsin $0.1 \mathrm{~m}$ phosphate buffer $(\mathrm{pH} 7.0)$ at scan rate of $30 \mathrm{mV} \mathrm{s}^{-1}$.

\begin{tabular}{ccccccc}
\hline Electrodes & $E_{1 / 2}$ & $E \mathrm{pc}$ & $E \mathrm{pa}$ & $\Delta E$ & \multirow{2}{*}{$v$ vs. $i$} & $v^{1 / 2}$ vs. $i$ \\
\cline { 2 - 5 } & \multicolumn{6}{c}{$\mathrm{mV}$} \\
\hline bare CFa) & -170.4 & -194.1 & -146.8 & 47.3 & non-linear & linear \\
TBO-HRP-CF & -142.3 & -220.4 & -64.1 & 156.3 & linear & non-linear \\
\hline
\end{tabular}

a) phosphare buffer $(0.1 \mathrm{M}, \mathrm{pH} 7.0)$ containing $0.1 \mathrm{mM} \mathrm{TBO}$ was used as electrolyte solution.

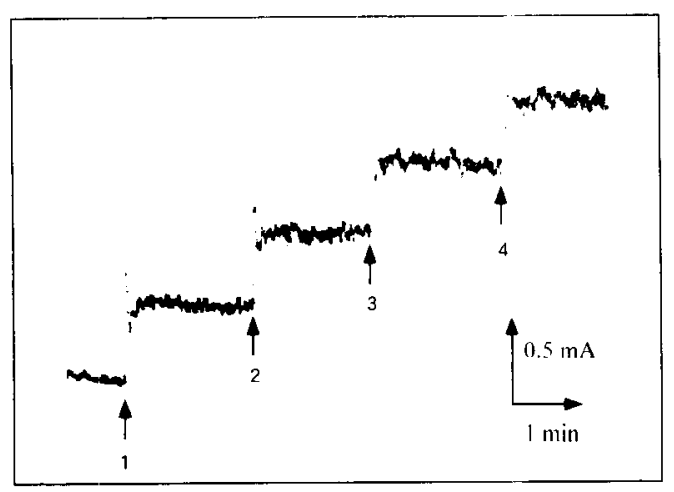

Fig. 2 Typical current-time responses of the TBO-HRP-CF electrode to successive addition of $0.5 \mathrm{mM}$ of $\mathrm{H}_{2} \mathrm{O}_{2}$ (1-4). The measurement was conducted under moderately stirred conditions in $0.1 \mathrm{M}$ [ phosphate buffer $(\mathrm{pH} 7.0)$ at $-0.4 \mathrm{~V}$ vs. $\mathrm{Ag} /$ $\mathrm{AgCl}$. 


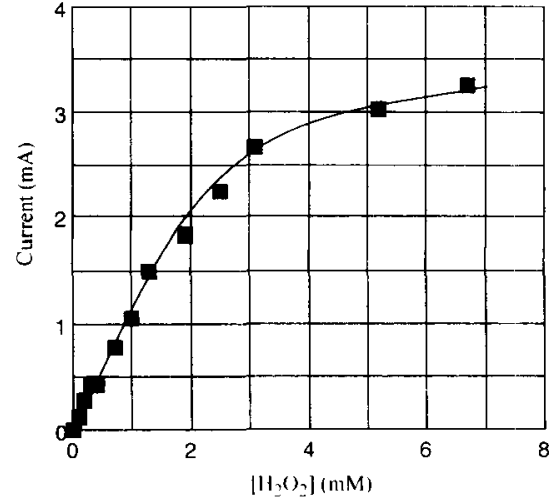

Fig. 3 Calibration curve of $\mathrm{H}_{2} \mathrm{O}_{2}$ with the TBO-HRP-CF electrode at the applied potential of $-0.4 \mathrm{~V}$ vs. $\mathrm{Ag} / \mathrm{AgCl}$.

TBO-HRP-CF at $-0.4 \mathrm{~V}$ to successive additions of $0.5 \mathrm{mM} \mathrm{H} \mathrm{H}_{2} \mathrm{O}_{2}$. The sensor exhibited relatively fast responses to $\mathrm{H}_{2} \mathrm{O}_{2}$ attaining a steady-state within $\sim 15 \mathrm{~s}$. It has been reported that the rate of mass transfer within the CF sheet is sufficiently fast, ${ }^{3)}$ which permits fast diffusion of the analytes from the bulk solution. Furthermore, in this case, the HRP and TBO are directly attached onto the CF surface via a relatively short-length spacer molecule, which would be preferable for the fast electron transfer at the electrode surface.

The calibration curves of the $\mathrm{H}_{2} \mathrm{O}_{2}$ sensor obtained at $-0.4 \mathrm{~V}$ (vs. $\mathrm{Ag} / \mathrm{AgCl}$ ) are shown in Fig. 3. The relationship between the steady-state current and $\mathrm{H}_{2} \mathrm{O}_{2}$ concentration was linear up to ca. $3 \mathrm{mM}$, and the detection limit for $\mathrm{H}_{2} \mathrm{O}_{2}$ was found to be $5 \times 10^{-5} \mathrm{M}(\mathrm{S} / \mathrm{N}=3)$. The sensitivity of the present $\mathrm{H}_{2} \mathrm{O}_{2}$ sensor is unfortunately lower than that of previously reported systems. ${ }^{9-13)}$ In order to enhance its sensitivity, the following trials may be required; 1) introduction of a sufficient amount of reactive groups at the $\mathrm{CF}$ surface to increase the enzyme loading and density of the mediator, 2) regulation of orientation of enzyme and mediator at the CF surface for smooth electronic communication, and 3) lowering the electronic noise (as shown in Fig. 2) probably due to the mechanical stirring and/or based on the non-faraday CF background currents.

Kinetic parameters for the amperometric detection of $\mathrm{H}_{2} \mathrm{O}_{2}$ with TBO-HRP-CF was evaluated by applying the results shown in Fig. 3 to the Lineweaver-Burk equation, as shown by eq (1),

$$
i^{-1}=\left(1+K_{\mathrm{m}}^{\mathrm{app}} C^{-1}\right) I_{\max ^{-1}},
$$

where $i$ is the steady state current, $C$ is the concentration of $\mathrm{H}_{2} \mathrm{O}_{2}, K_{\mathrm{m}}$ app is the apparent Michaelis constant, and $I_{\max }$ is the maximum current response. A good linear relation was obtained between $i^{-1}$ and $C^{-1}$, and $K_{\mathrm{m}}$ app was calculated to be $5.73 \mathrm{mM}$ (at $-0.4 \mathrm{~V}$ vs. $\mathrm{Ag} / \mathrm{AgCl}$ ).

The preliminary storage stability of the TBO-HRP-CF stored at $4^{\circ} \mathrm{C}$ was examined by periodically checking its relative activity. The bioelectrocatalytic activity of the
TBO-HRP-CF decreased rather rapidly, and after 5 days (60 samples tests) the sensor maintained ca. $50 \%$ of the response values at the beginning of the experimental period. The light sensitivity and the chemical instability of the TBO are probably the principal reasons causing the decreased sensitivities of the sensor.

\section{Conclusions}

The electron mediator (TBO) and HRP were successfully co-immobilized on the surface of the porous $\mathrm{CF}$ by a simple one-step procedure using cyanuric chloride as the linking agent by the reaction of the amino groups of TBO and HRP. The immobilized TBO efficiently mediates the electrons from the CF to the HRP active center, and permits amperometric responses to $\mathrm{H}_{2} \mathrm{O}_{2}$ with a rapid response time of $\sim 15 \mathrm{~s}$. Since the porous $\mathrm{CF}$ is very useful in a couloamperometric cell ${ }^{8)}$ and flowthrough reactor, ${ }^{12,13)}$ further studies in this area are now underway.

\section{Acknowledgment}

This research was supported in part by a Grant-in-Aid for Scientific Research from the Ministry of Education, Science and Culture of Japan (No.11771416), and a part of this research was also supported by the High-Tech Research Center of Saitama Institute of Technology.

\section{References}

1) J. -J. Sun, H. -Q. Fang, and H. -Y. Chen, Analyst, 123, 1365 (1998).

2) B. Wang, B. Li, Z. Wang, G. Xu, Q. Wang, and S. Dong, Anal. Chem., 71, 1935 (1999).

3) C. Lei and J. Deng, Anal. Chem., 68, 3344 (1996).

4) J. Quan, Y. Liu, H. Liu, T. Yu, and J. Deng, Biosens. Bioelectron., 12, 1213 (1997).

5) C. Ruman, F. Yang, C. Lei, and J. Deng, Anal. Chem ., 70, 1721 (1998).

6) R.W. Murray, in Electroanalytical Chemistry, Vol. 13. A. J. Bard, Editor, p.191, Mercel Dekker, New York (1984).

7) T. Osa, in New Challenges in Organic Chemistry, T. Osa, Editor, p.185, Gorton and Breach Scientific Publishers, Amsterdam (1998).

8) S. Uchiyama, M. Ono, S. Suzuki, and O. Hamamoto, Anal. Chem., 60, 1835 (1988).

9) F. Mizutani and S. Yabuki, Sens. Actuators B, 24/25, 76 (1995).

10) S. Uchiyama, Y. Hasebe, and M. Tanaka, Electroanalysis, 9, 176 (1997).

11) F. Tobalina, F. Pariente, L. Hernandez, H. D. Abruna, and E. Lorenzo, Anal. Chim. Acta, 358, 15 (1998).

12) U. Rudel, O. Geschke, and K. Cammann, Electroanalysis, 8, 1135 (1996).

13) M. Torimura, M. Mochizuki, K. Kano, T. Ikeda, and T. Ueda, Anal. Chem., 70, 4690 (1998).

14) B. Persson and L. O. Gorton, J. Electroanal. Chem., 292, 115 (1990).

15) D. D. Schelereth, E. Katz, and H. -L. Schmidt, Electroanalysis, 7, 46 (1995). 